More maps, more users, more devices means more cartographic challenges

Griffin, Amy L ; Fabrikant, Sara I

DOI: https://doi.org/10.1179/0008704112Z.00000000049

Posted at the Zurich Open Repository and Archive, University of Zurich ZORA URL: https://doi.org/10.5167/uzh-78044

Journal Article

Published Version

Originally published at:

Griffin, Amy L; Fabrikant, Sara I (2012). More maps, more users, more devices means more cartographic challenges. Cartographic Journal, 49(4):298-301.

DOI: https://doi.org/10.1179/0008704112Z.00000000049 


\section{Editorial \\ More Maps, More Users, More Devices Means More Cartographic Challenges}

Spatial information is pervasive in today's world. More people are both making and using maps for more purposes than ever before. For example, in February 2012 alone, Google Maps had 65 million viewers (New York Times, 2012). An indicator of just how embedded maps, particularly those distributed through smart phones, have become in daily life is the furore that erupted over Apple's decision to replace the Google Maps app available for iPhones with its own, not-quite-ready-for-primetime app in September 2012. Williamson et al. (2006) and Rajabifard et al. (2010) have promoted the idea of a 'spatially enabled society' in which location and place-based information is widely available to citizens, governments and businesses, and can be used to organize their activities. One important question remains: How should place-based information be made accessible to an increasingly mobile information society?

It is easier than ever for people to make maps, and many maps are now produced to support personal and community activities in addition to the maps that have traditionally been used to support scientific, technical or organisational activities. Some of these maps are used to make decisions about where to go and how to get there (e.g., Yelp or Poynt; Google Maps, MapQuest and Bing Maps, respectively). Others are used to support decisions across a wide variety of domains, including emergency management (MacEachren et al., 2011; Tomaszewski, 2011), managing the movement of people and other objects in the real world (Wood et al., 2011), and to argue for the implementation of particular public policy options instead of others (van Herzele and van Woerkum, 2011).

The growth of pervasive map making and map use, driven largely by the information collection and distribution capabilities of the Internet and the widespread availability of affordable devices for collecting location information such as GPS (Haklay et al., 2008), puts a variety of types of spatial information in the hands of most everyone, on devices ranging from desktop computers to navigation devices in cars, tablet computers, and smart phones. The digital environment also allows naïve and expert cartographers to rapidly create innovative representations of spatial information and to disseminate them to a broad and large audience that is connected to the Internet. The diversity of devices, map uses and users, and forms of representation opens up a wide array of challenges for map makers and cartographers, whether formally trained or not. Among them is the design of useful, usable visual representations for these new use contexts, a challenge highlighted by Tsou (2011).

Addressing this problem requires intersecting sets of knowledge: about how the users themselves think, reason and work (cognition), the tasks that representations are meant to support (behaviour), as well as the technologies themselves and how cartographic practice and principles are instantiated within specific technologies (representation). While excellent work addressing one or more domains of that knowledge base is being undertaken within a variety of disciplinary domains, less attention has been paid to the integration of these knowledge sets to inform representation and tool design. As yet, there is still a need to develop a sound theoretical base to support the construction and use of cognitively adequate and perceptually salient visual displays of spatial information, particularly for representations that go beyond traditional, paper-based maps (Fabrikant and Lobben, 2009). Thereafter, a key challenge lies in how to get this knowledge into the hands of map makers themselves. Small, but important steps have been made in this direction through the development of web-based guides such as ColorBrewer (Brewer et al., 2003; Harrower and Brewer, 2003).

The International Cartographic Association (ICA) Commission on Cognitive Visualization ( $\mathrm{CogVis}$ ) was established in July 2011 in an effort to provide an international and interdisciplinary organisational framework to support the development of this theory base. It seeks to engage scholars from relevant disciplines (e.g., GIScience, cognitive science, information visualisation, visual design, human-computer interaction and others) in achieving this goal by bringing them together to exchange ideas, methods and expertise. In so doing, we aim to collaborate with other ICA Commissions whose remit is important for achieving a cognitively adequate human-centred cartographic design.

The idea for this special issue arose from one such collaboration with the ICA Commission on Map Design, whom we invited to co-organize the 2012 iteration of the Cognition, Behaviour, Representation session stream at the Annual Meeting of the Association 
of American Geographers in New York City. This series of sessions has its origin in two sessions on cognitive issues in geographic information visualisation organized by Sara Fabrikant and Amy Lobben at the 2008 AAG Annual Meeting, and which resulted in a special issue of Cartographica (44/3). The session series has appeared under the title of Cognition, Behaviour, Representation since 2009. This series of sessions has been sponsored by the Cartography, GIS, and Environmental Perception and Behavioural Geography Specialty Groups of the AAG. Topics of interest for the 2012 call for papers included:

- geovisualisation design, implementation, and use (technical and/or cognitive issues);

- application of geovisualisation displays and tools to understanding spatial cognition;

- methods for and application of cognitive theories and methods to understanding issues in geographic research (including fMRI);

- human-geovisualisation interaction research;

- cognition of space-time representations;

- wayfinding and navigation;

- cognitive map design research;

- usability of digital geographic displays.

In 2012, the series was comprised of seven sessions over two days, with presentations from 41 scholars based in seven countries, and included the first interactive short paper session of the series. When compared with the first year of this session series, which was comprised of nine presenters in 2008, this demonstrates both strong growth and increasing scholarly interest in this area. After the conference, authors were invited to submit full papers based upon their oral presentations to the special issue. Eleven papers were submitted for consideration, and after peer review by two to three external reviewers, as well as the special issue editors, seven papers were accepted for publication in this issue.

The papers from this special issue address various aspects of the interrelationships between the design of cartographic representations, how people think when using them, and the behaviours that these uses support. Gretchen Culp most directly focuses on the design of cartographic representations themselves. She highlights the fact that a given map may not work for all map readers as some map readers have colour vision impairments. In particular, she argues that cartographers have done little to accommodate the needs of individuals with acquired (blue-green) colour vision impairments. She presents an algorithm that can be used to recolour existing maps to accommodate map readers with either an acquired or inherited (red-green) colour vision impairment. While she has not yet evaluated the efficacy of the algorithm with map readers, initial tests with colour vision impairment simulators indicate that her algorithm shows great promise. As such, the use of her algorithm is likely to enable colour vision impaired map readers to more successfully engage perceptually and cognitively with a wider range of maps.

Two studies explore the role of maps in helping people to move through the environment. Michaela Skiles and Jeffrey Howarth experimentally studied the role that spatial information on road signs played in helping people develop a mental map of the area through which they were moving. Janet Speake and Stephen Axon investigated how the use of wayfinding technologies such as satellite navigation systems (i.e., GPS/Sat Nav) influenced users' attitudes towards traditional maps and the potential implications of these attitudes for cartographic literacy and spatial awareness.

Skiles and Howarth manipulated the configuration of spatial information presented on road signs that a driver would typically see while navigating across a road network. In so doing, their study focused on the relationship between (spatial) cognition and the design of representations of spatial information. They found that while all of the designs they tested enabled participants to make accurate turn decisions, when compared to road signs designed according to the US Federal Highway Administration's design standard, which separates town and road information in time and space (on separate signs), signs that presented both road and town information (i.e., those that were maplike) improved individuals' capacities to passively improve their mental maps of the area through which they were moving.

Speake and Axon's contribution also probed the role of spatial information in navigation. Their research is primarily centred on the interaction of behaviour (what people do with Sat Nav) and cognition (effects on respondents' ability to use other spatial information representations). They found, for example, that when respondents were actively engaging with Sat Nav, they said that they paid less attention to the real world environment around them. They also found that many respondents believed that relying on Sat Nav would eventually atrophy their ability to read traditional (paper) maps. A potentially interesting follow-up study that could build upon both Skiles and Howarth's and Speake and Axon's work might look at whether the use of Sat Nav leads navigators to attend less frequently to spatial information in the environment (e.g., that found on signs), and thereby decrease their incidental spatial learning.

Three studies examined different aspects of the role of the design of cartographic representations on how map readers understand the information in maps (cognition). Anna-Katharina Lautenschütz experimentally examined which visual characteristics were important in influencing inferences map readers made about movement patterns in visualisations of movement data. Raechel Bianchetti and colleagues worked with map readers to 
determine the extent to which the design of emergency management map symbol sets reflected map readers' understanding of relationships between feature types. Ian Muehlenhaus's research also turned its focus on the relationship between the cartographer's intentions and map reader conceptions by manipulating rhetorical styles used to represent a phenomenon and measuring map readers' understanding of the maps.

Lautenschütz's work is driven by a desire to design representations of movement patterns that visually emphasize those movement path elements that are most important for making inferences about the cause of that movement in such a way that the representations are both perceptually salient and cognitively adequate. To determine what these path elements are, she conducted an experiment that manipulated geographic and behavioural context and asked participants to make inferences (cognition) based upon these representations. Her experiment determined that the visual character of the line and the shape of the path were the elements that were most commonly used when making inferences. This is an interesting result in light of the fact that some line characteristics that are commonly important when computers are used to make inferences about movement patterns - in data mining algorithms, for example - are not used by humans (e.g., change of direction of the movement).

Bianchetti and colleagues also probed the inferences map readers made from map symbols. Their research was directed to assessing the extent to which the symbol sets that collectively form two emergency response symbol standards reflected the natural categories map readers used to group related phenomena. Their work demonstrated that several features of symbol design (representation) influenced the way that map readers grouped symbols together, based on their understanding of what the symbol represented (cognition): iconicity, and the repeated use and modification of a central symbol. They contend that symbol designs (and standards) that better reflect the natural categories that map readers use to think about phenomena may enhance the transferability of the symbols between emergency response contexts, and thereby make cross-border response operations more efficient and less prone to problems arising from miscommunication.

Rather than focusing on an individual symbol or a particular symbol set, Muehlenhaus analysed complete map styles. He identified four rhetorical map styles and investigated how rhetorical style (i.e., the overall design of the representation) might affect map reader opinions about the map's topic, their level of trust in the data, and the memorability of the map, as well as how much map readers liked the map. In so doing, he highlights an important dimension of how map readers engage with maps that is not always acknowledged in empirical studies of map use: the role of emotion in influencing cognition. He notes that evoking an emotional response is a key strategy through which rhetoric is successful in persuading a person to believe something based on information that is presented in the argument, and argues for the need to move beyond measuring how accurately map readers extract information from maps, to consider their potential power to persuade, and the memorability of the arguments they present.

Finally, Robert Roth's synthesis of taxonomies of cartographic interaction primitives provides an excellent example of exploring the interrelationships between the design of cartographic representations, how people think when using them, and the behaviours that these uses support. Specifically, he employs Norman's (1988) stages of action model to organize his discussion of existing taxonomies of interaction, mostly developed outside of cartography. That model incorporates the design of the representation (interactive maps - the operand, using Roth's terminology), user behaviour (what s/he wants to do - the objective, using Roth's terminology), and cognition (how users evaluate the result of their interaction with a map). He argues that his framework can be used to understand how different studies of cartographic interaction relate to each other and can thereby be used to, over time, build a set of guidelines for the design of interactive maps that work well for map readers.

We hope that this set of papers demonstrates the complexity of designing maps for today's rapidly changing contexts, with maps used by many different types of people to accomplish many different types of tasks, on many different types of devices. Now, more than ever, we need to attend to the cognitive, behavioural and representational perspectives on cartography.

Amy L. Griffin

School of Physical, Environmental and Mathematical Sciences, University of New South Wales, Canberra

Australia

Email: a.griffin@adfa.edu.au

Sara Irina Fabrikant

Department of Geography University of Zürich, Switzerland

Email: sara.fabrikant@geo.uzh.ch

\section{BIOGRAPHICAL NOTES}

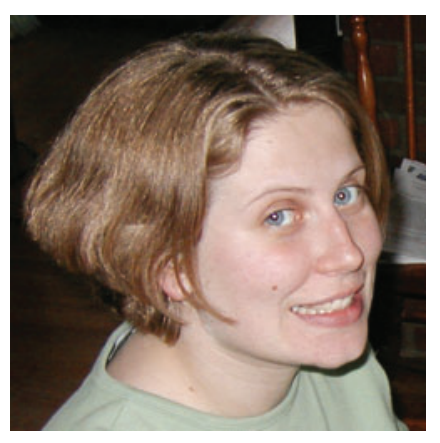

Dr Amy L. Griffin is a Senior Lecturer at the School of Physical, Environmental and Mathematical Sciences at the University of New South Wales in Canberra, Australia. Along with Associate Professor Sara Fabrikant, she is a co-chair of the ICA 
Commission on Cognitive Visualisation. Her cartographic research interests centre on how people use and think with representations of spatial information.

\section{ACKNOWLEDGEMENTS}

This special issue could not have been produced without the assistance of many individuals. We would like to thank our co-organizers of the Cognition, Behaviour, Representation series (Sarah Battersby, Scott Bell and Kirk Goldsberry), the leadership of the ICA Commission on Map Design (Ken Field, Alex Kent, Bernie Jennie and Anja Hopfstock), the production team at Maney Press, and of course, the many reviewers who took the time to carefully review the submitted manuscripts and who provided constructive critiques that helped the authors improve their work. Last, but not least, we thank the authors for supporting the Commission and submitting their work to this special issue.

\section{REFERENCES}

Brewer, C. A., Hatchard, G. W. and Harrower, M. A. (2003). 'ColorBrewer in Print: a catalog of color schemes for maps', Cartography and Geographic Information Science, 30, pp. 532 .

Fabrikant, S. I. and Lobben, A. (eds.) (2009). Special Issue on Cognitive Issues in Geovisualization. Cartographica, 44.
Haklay, M., Singleton, A. and Parker, C. (2008). 'Web Mapping 2.0: the neogeography of the GeoWeb', Geography Compass, 2, pp. 2011-2039.

Harrower, M. A. and Brewer, C. A. (2003). 'ColorBrewer.org: an online tool for selecting color schemes for maps', The Cartographic Journal, 40, pp. 27-37.

MacEachren, A. M., Jaiswal, A., Robinson, A. C., Pezanowski, S., Savelyev, A., Mitra, P., Zhang, X. and Blanford, J. (2011). 'SensePlace2: GeoTwitter analytics support for situational awareness', In Visual Analytics Science and Technology (VAST), 2011 IEEE Conference, Providence, RI, USA, Oct 23-28. pp. 181-190.

New York Times. (2012). Facing Fees, Some Sites are Bypassing Google Maps. http://www.nytimes.com/2012/03/20/technology/ many-sites-chart-a-new-course-as-google-expands-fees.html?pagewan ted $=$ all $\& \_r=0$. (accessed 22 October 2012$)$.

Rajabifard, A., Crompvoets, J., Kalantari, M. and Kok, B. (eds) (2010), Spatially Enabled Society: Research, Emerging Trends, and Critical Assessment, Leuven University Press, Belgium.

Tomaszewski, B. (2011). 'Situation awareness and virtual globes: Applications for disaster management', Computers \& Geosciences, 37 , pp. 86-92.

Tsou, M-H. (2011). 'Revisiting web cartography in the United States: the rise of user-centered design', Cartography and Geographic Information Science, 38, pp. 250-57.

van Herzele, A., and van Woerkum, C. (2011). 'On the argumentative work of map-based visualization', Landscape and Urban Planning, 100, pp. 396-99.

Williamson, I., Wallace, J. and Rajabifard, A. (2006). 'Spatially enabling governments: a new vision for spatial information', Towards a 2015 Vision of Land, Taipei, Taiwan, Oct 24-25.

Wood, J., Slingsby, A. and Dykes, J. (2011). 'Visualizing the dynamics of London's bicycle hire scheme', Cartographica, 46, pp. 239 251. 